\title{
Design and Characterization of Polymeric Floating Microspheres of
}

\section{Levofloxacin Hemihydrate.}

\author{
Vaibhav Kulkarni ${ }^{*}$, Sagar Arekar² ${ }^{2}$ Lalit Sonawane ${ }^{3}$ \\ 1*, 2, Department of Quality Assurance, SVB's College of Pharmacy, Dombivli (E), M.S., \\ India. \\ ${ }^{3}$ Department of Quality Assurance, Maharashtra College of Pharmacy, Nilanga, M.S., India.
}

The complex of Levofloxacin and Chitosan lead to formation of water soluble complex. This complex of Levofloxacin was then formulated into floating beads calcium alginate with maximum entrapment of Levofloxacin found to be about $75 \%(f 10)$ and the entrapment was found to be significantly higher as compared to the other formulations ( $\mathrm{f} 1$ to $\mathrm{f9}$ ). In-Vitro Release studies of the beads f10 was found to significantly improve the release of Levofloxacin as compared to other formulations. The mean particle size of f10 microspheres and surface morphology were determined by SEM Resulting in Porous and Rough Surface of microspheres. The drug release kinetics were studied as zero order, first order , Higuchi , Koresmeyer-Peppas equations, good linearity was found in Higuchi's Equation $\left(R^{2}=0.9310\right)$ indicating the release of the drug from Microspheres is based on Fickian Diffusion .

Key words: Levofloxacin, Chitosan, Calcium Alginate, Microspheres, release kinetics, SEM, Fickian Diffusion

\section{Introduction}

Floating drug delivery systems (FDDS) or hydro dynamically controlled systems are low-density systems that have sufficient buoyancy to float over the gastric contents and remain buoyant in the stomach without affecting the gastric emptying rate for a prolonged period of time. While the system is floating on the gastric contents, the drug is released slowly at the desired rate from the system. After release of drug, the residual system is emptied from the stomach. This results in an increased Gastric retention time and a better control of the fluctuations in plasma drug concentration. However, besides a minimal gastric systems have been developed based on beads, granules, powders, capsules, tablets, laminated films and hollow microspheres content needed to allow the proper achievement of the buoyancy retention principle, a minimal level of floating force (F) is also required to keep the dosage form reliably buoyant on the surface of the meal Many buoyant.[1-5] 
While the system is floating on the gastric contents, the drug is released slowly at the desired rate from the system. After release of drug, the residual system is emptied from the stomach. This results in an increased Gastric retention time and a better control of the fluctuations in plasma drug concentration. However, besides a minimal gastric content needed to allow the proper achievement of the buoyancy retention principle, a minimal level of floating force $(\mathrm{F})$ is also required to keep the dosage form reliably buoyant on the surface of the meal Many buoyant systems have been developed based on beads, granules, powders, capsules, tablets, laminated films and hollow microspheres the drugs that is majorly absorbed from stomach or proximal part of the intestine. The pattern of motility is however distinct in the two states. During the fasting state an interdigestive series of electrical events take place, which cycle both through stomach and intestine every 2 to 3 hours. This is called the interdigestive myloelectric cycle or migrating myloelectric cycle (MMC), which are further divided into following 4 phases are:

1. Phase I (basal phase) It lasts from 40 to 60 minutes with rare contractions.

2. Phase II (preburst phase) It lasts for 40 to 60 minutes with intermittent action potential and contractions. As the phase progresses the intensity and frequency also increases gradually.

3. Phase III (burst phase) lasts for 4 to 6 minutes. It includes intense and regular contractions for short period. It is due to this wave that all the undigested material is swept out of the stomach down to the small intestine. It is also known as the housekeeper wave.

4. Phase IV It is a period of transition from phase III and phase I and last for 0 to 5 minutes. [5-7]

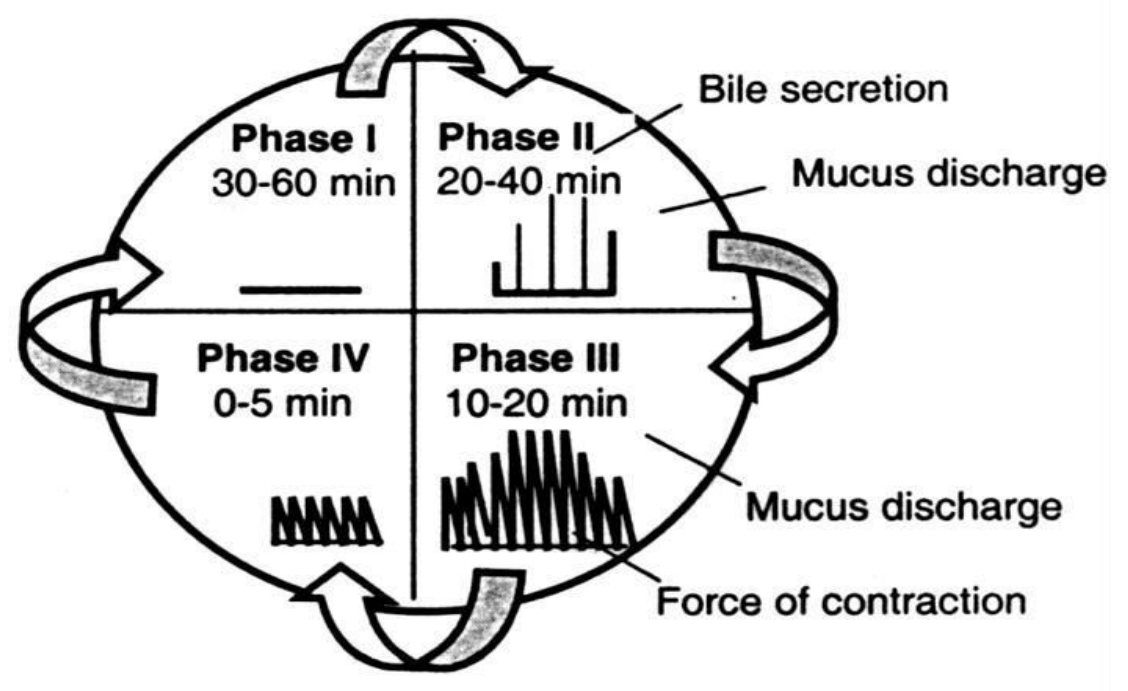

Figure 1.Interdigestive myloelectric cycle or migrating myloelectric cycle (MMC). 


\section{Mechanism of floating systems}

Various attempts have been made to retain the dosage form in the stomach as a way of increasing the retention time. These attempts include introducing floating dosage forms

1. Gas-generating systems

2. Swelling or expanding

3. Mucoadhesive systems

4. High-density systems

5. Low density system

Floating drug delivery systems (FDDS) have a bulk density less than gastric fluids and so remain buoyant in the stomach without affecting the gastric emptying rate for a prolonged period of time. The drug is released slowly at the desired rate from the system. After release of drug, the residual system is emptied from the stomach. This results in an increased GRT and a better control of the fluctuations in plasma drug concentration. However, besides a minimal gastric content needed to allow the proper achievement of the buoyancy retention principle, a minimal level of floating force $(\mathrm{F})$ is also required to keep the dosage form reliably buoyant on the surface of the meal. To measure the floating force kinetics, a novel apparatus for determination of resultant weight has been reported in the literature. The apparatus operates by measuring continuously the force equivalent to $\mathrm{F}$ (as a function of time) that is required to maintain the submerged object. The object floats better if $\mathrm{F}$ is on the higher positive side. This apparatus helps in optimizing FDDS with respect to stability and durability of floating forces produced in order to prevent the drawbacks of unforeseeable intragastric buoyancy capability variations.[8-21]

$\mathrm{F}=\mathrm{F}$ (buoyancy) - F (gravity)

$$
=(\mathrm{Df}-\mathrm{Ds}) \mathrm{gv} \quad--(1)
$$

Where, $\mathrm{F}=$ total vertical force,

Df $=$ fluid density,

Ds = object density,

$\mathrm{v}=$ volume of GI fluid and

$\mathrm{g}=$ acceleration due to gravity

\subsection{Levofloxacin Hemihydrate}

Levofloxacin and other fluoroquinolones are valued for their broad spectrum of activity, excellent tissue penetration, and for their availability in both oral and intravenous formulations. Levofloxacin is used alone or in combination with other antibacterial drugs to treat certain bacterial infections including pneumonia, urinary tract infections, and abdominal infections. Levofloxacin and other fluoroquinolones are generally well tolerated, but in rare instances have produced serious adverse reactions such as spontaneous tendon ruptures and irreversible peripheral neuropathy. 


\section{Methods:}

Standard Levofloxacin Hemihydrate LR and polymer Chitosan purchased form Research-Lab Fine Chemical Industries and Sodium Alginate, sodium bicarbonate, calcium carbonate Procured from LOBA Chemie Pvt .Ltd. Mumbai

\section{Preparation and Optimization of Levofloxacin and Chitosan complex}

Levofloxacin was mixed with Chitosan in different proportions and the optimum proportion of the drug and the polymer was established to get the water soluble complex. UV Spectrophotometer for solubility analysis of the maximum Levofloxacin dissolves in water in presence of Chitosan. All the floating beads formulation of Levofloxacin dissolves in water. Wavelength scanning from $400 \mathrm{~nm}$ to $200 \mathrm{~nm}$. Peaks should be shows at a $288 \mathrm{~nm}$ of the all floating beads formulation Chitosan in different ratios they as following. The soluble complex of Levofloxacin and Chitosan was then utilized with various Proportions of Sodium alginate, Sodium bicarbonate and calcium carbonate to get Maximum entrapment of Levofloxacin in the floating beads. Factorial design was applied to design the experiment and optimization of maximum entrapment of Levofloxacin in Microspheres.

\section{Preparation of calcium alginate Levofloxacin Floating Microspheres}

Aqueous solution of Sodium alginate solution $(2 \% 2 \mathrm{~g} / 100 \mathrm{ml}$ of water w/v) was prepared by suspending $2 \mathrm{gm}$ of Sodium alginate in $100 \mathrm{ml}$ of distilled water. The suspension was kept under continuous stirring using magnetic stirrer till homogenous solution was obtained. Complex of Levofloxacin with Chitosan was prepared by mixing $1.0 \mathrm{gm}$ of Levofloxacin and concentration various formulation chitosan . The complex (52gm) was then mixed with $1.0 \mathrm{gm}$ sodium bicarbonate and $1.6 \mathrm{gm}$ of calcium carbonate. The mixture of levofloxacin , chitosan, Sodium bicarbonate and Calcium carbonate obtained in step " $\mathrm{b}$ " was then added to $50 \mathrm{ml}$ of Sodium alginate solution and stirred thoroughly to get uniformly suspended mixture. Dissolved $2 \mathrm{gm}$ of Calcium chloride in about $80 \mathrm{ml}$ of distilled water and made up the volume to $100 \mathrm{ml}$ to get $2 \% \mathrm{w} / \mathrm{v}$ solution of Calcium chloride. The floating beads of Levofloxacin we prepared by adding drop wise the mixture obtained in step " $\mathrm{c}$ " under stirring condition. The beads obtained in step were separated by filtration and weighed. The Wet beads were then dried at $40^{\circ} \mathrm{C}$ for $2 \mathrm{hrs}$. The beads were then kept at room temperature for overnight for further dried to form microspheres. (Table $1.0)$

\section{Encapsulation Efficiency}

$1 \mathrm{~g}$ of Levofloxacin, weight of dried CLFB different formulation of Levofloxacin determination of following parameter for drug loading and encapsulation efficiency.

a) $\%$ drug loading (DL) $=$ Weight of Levofloxacin in beads/weight of beads $* 100$

b) $\%$ theoretical loading $(\mathrm{TL})=$ Weight of Levofloxacin added/Weight of Levofloxacin added + Weight of Polymer added $\times 100$

c) $\%$ entrapment efficiency (EE) $=\%$ Drug Loading $/ \%$ Theoretical Loading $\times 100$ 


\begin{tabular}{|c|c|c|c|c|c|c|}
\hline $\begin{array}{c}\text { Formulation / } \\
\text { Content }\end{array}$ & $\begin{array}{c}\mathrm{LV} \\
(\mathrm{gm})\end{array}$ & $\begin{array}{c}\mathrm{CH} \\
(\mathrm{gm})\end{array}$ & $\begin{array}{c}\mathrm{CC} \\
(\mathrm{gm})\end{array}$ & $\begin{array}{r}\mathrm{SB} \\
(\mathrm{gm})\end{array}$ & $\begin{array}{c}\mathrm{CA} \\
(\mathrm{gm})\end{array}$ & $\begin{array}{c}\text { SA } \\
(\mathrm{gm})\end{array}$ \\
\hline $\mathrm{F} 1$ & $1.0 \mathrm{gm}$ & - & $0.5 \mathrm{gm}$ & $1.0 \mathrm{gm}$ & $2 \%$ & $2 \%$ \\
\hline F2 & $1.0 \mathrm{gm}$ & - & $1.0 \mathrm{gm}$ & $1.0 \mathrm{gm}$ & $2 \%$ & $2 \%$ \\
\hline F3 & $1.0 \mathrm{gm}$ & $0.5 \mathrm{gm}$ & $0.5 \mathrm{gm}$ & $1.0 \mathrm{gm}$ & $2 \%$ & $2 \%$ \\
\hline F4 & $1.0 \mathrm{gm}$ & $0.5 \mathrm{gm}$ & $1.0 \mathrm{gm}$ & - & $2 \%$ & $2 \%$ \\
\hline F5 & $1.0 \mathrm{gm}$ & -- & $1.0 \mathrm{gm}$ & - & $2 \%$ & $2 \%$ \\
\hline F6 & $1.0 \mathrm{gm}$ & $1.0 \mathrm{gm}$ & $1.0 \mathrm{gm}$ & $1.0 \mathrm{gm}$ & $2 \%$ & $2 \%$ \\
\hline F7 & $1.0 \mathrm{gm}$ & - & - & $1.0 \mathrm{gm}$ & $2 \%$ & $2 \%$ \\
\hline F8 & $1.0 \mathrm{gm}$ & $0.5 \mathrm{gm}$ & $0.5 \mathrm{gm}$ & $0.5 \mathrm{gm}$ & $2 \%$ & $2 \%$ \\
\hline F9 & $1.0 \mathrm{gm}$ & $0.5 \mathrm{gm}$ & $1.0 \mathrm{gm}$ & $0.5 \mathrm{gm}$ & $2 \%$ & $2 \%$ \\
\hline F 10 & $1.0 \mathrm{gm}$ & $1.0 \mathrm{gm}$ & $1.0 \mathrm{gm}$ & $0.5 \mathrm{gm}$ & $2 \%$ & $2 \%$ \\
\hline F11 & $1.0 \mathrm{gm}$ & - & $0.5 \mathrm{gm}$ & $0.5 \mathrm{gm}$ & $2 \%$ & $2 \%$ \\
\hline & & & & & & \\
\hline
\end{tabular}

Table 1.0 Formulation of Floating Microspheres with composition of different excipients

LV = Levofloxacin , C.C. $=$ calcium carbonate, S.B. = sodium bicarbonate, $\mathrm{CH}=$ Chitosan, S.A. $=$ Sodium alginate solution $2 \%, C A=$ Calcium chloride solution $2 \%$

\section{DSC and TGA analysis}

Differential Scanning Calorimetry and Thermal Gravimetry Analysis for Sodium Alginate Levofloxacin Hemihydrate Floating Microspheres Formulation F10- melting point of standard Levofloxacin is $215 \mathrm{C}^{\circ}$. Scanning range is 30 to $320^{\circ}$ with respect to heating rate $10^{\circ} \mathrm{C}$ per minutes by Pyris series DSC 6000.

\section{FT-IR Study}

Drug and Drug polymer interaction were studied by FT-IR Spectroscopy. The infrared Spectra of levofloxacin and Drug loaded Microspheres were recorded on FT-IR (sican2301).The sample were prepared on $\mathrm{KBr}$ press and the spectera Were recorted over the wave range of 4,000 to $500 \mathrm{~cm}^{-1}$. 


\section{Particle size analysis}

Particle size of microspheres were determined by optical microscopy .Mean particle size was determined for all formulations of microspheres.

\section{Scanning electron microscopy (SEM)}

The Surface and cross -section morphologies of the F10 Beads Were observed using a (SEM) (JSM-6490 LA,JEOL,TOKYO,JAPAN) Operated at an acceleration voltage of $25 \mathrm{kv}$. The beads were made conductive by sputtering thin coat of platinum under vacuum using Jeol JFC-1600 Auto Fine Coater And Then Images Were Recorded At Different Magnifications.

\section{Buoyancy Test}

The obtained beads were studied for buoyancy and floating time using USP Apparatus 2(paddle type ).one hundred beads were placed in 900ml of 0.1NHCL (PH-1.2)Containing $0.02 \%$ Tween 80 and agitated at 50rpm,temperature was maintained at $37 \mathrm{C}^{0}$.

\section{In-vitro release profile of Calcium Alginate Levofloxacin Floating Microspheres}

Release of Levofloxacin from the floating Microspheres were determined by dissolution testing method using. Using U.S.P. Type I Apparatus using 0.1N HCL pH 1.2 at $37 \pm 0.5$ ${ }^{\circ} \mathrm{C}$ and 100rpm .Concentrations of drug were analyzed by U.V.

\section{Drug release kinetics}

The drug release kinetics of F10 was studied by various kinetic models as zero order, first order ,Higuchi's model , Koresmeyer Peppas model.

\section{Results}

\section{Preparation of calcium alginate Levofloxacin Floating Microspheres}

Microspheres of F1 to F11 were formulated by using different concentrations of Levofloxacin, Sodium Alginate, Chitosan and other excipients as mentioned in Methodology . Microspheres' were dried and stored at room temperature.
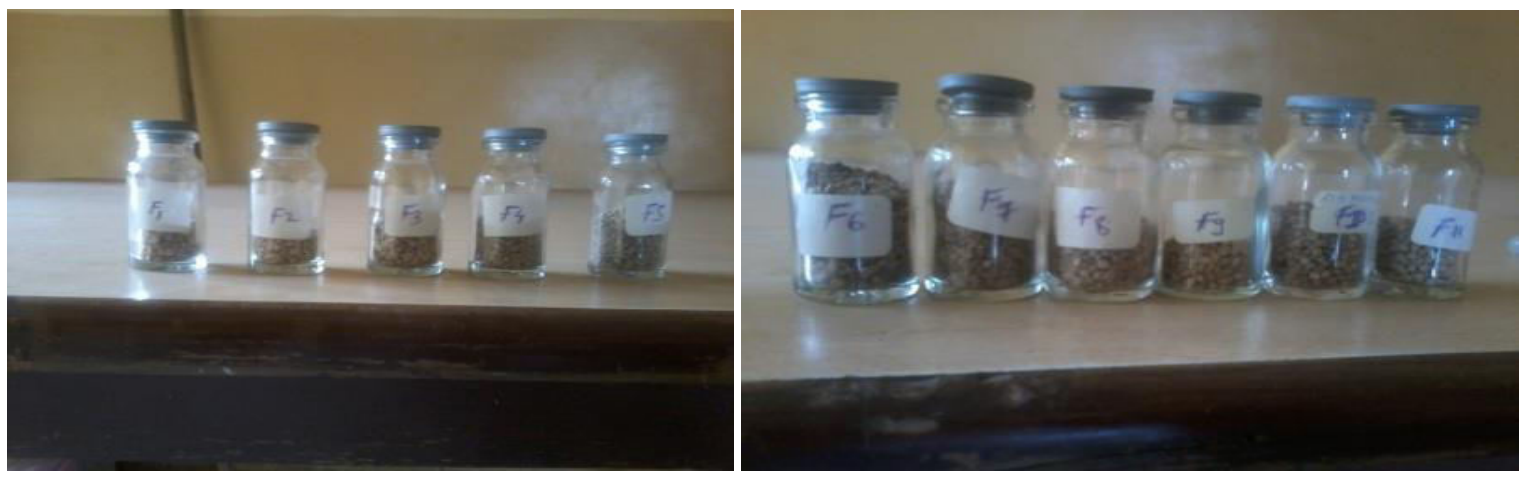

Figure 2. Dried Microspheres of F1, F2,F3, F4 , F5, F6, F7, F8,F9,F10 and F11 


\section{Encapsulation Efficiency}

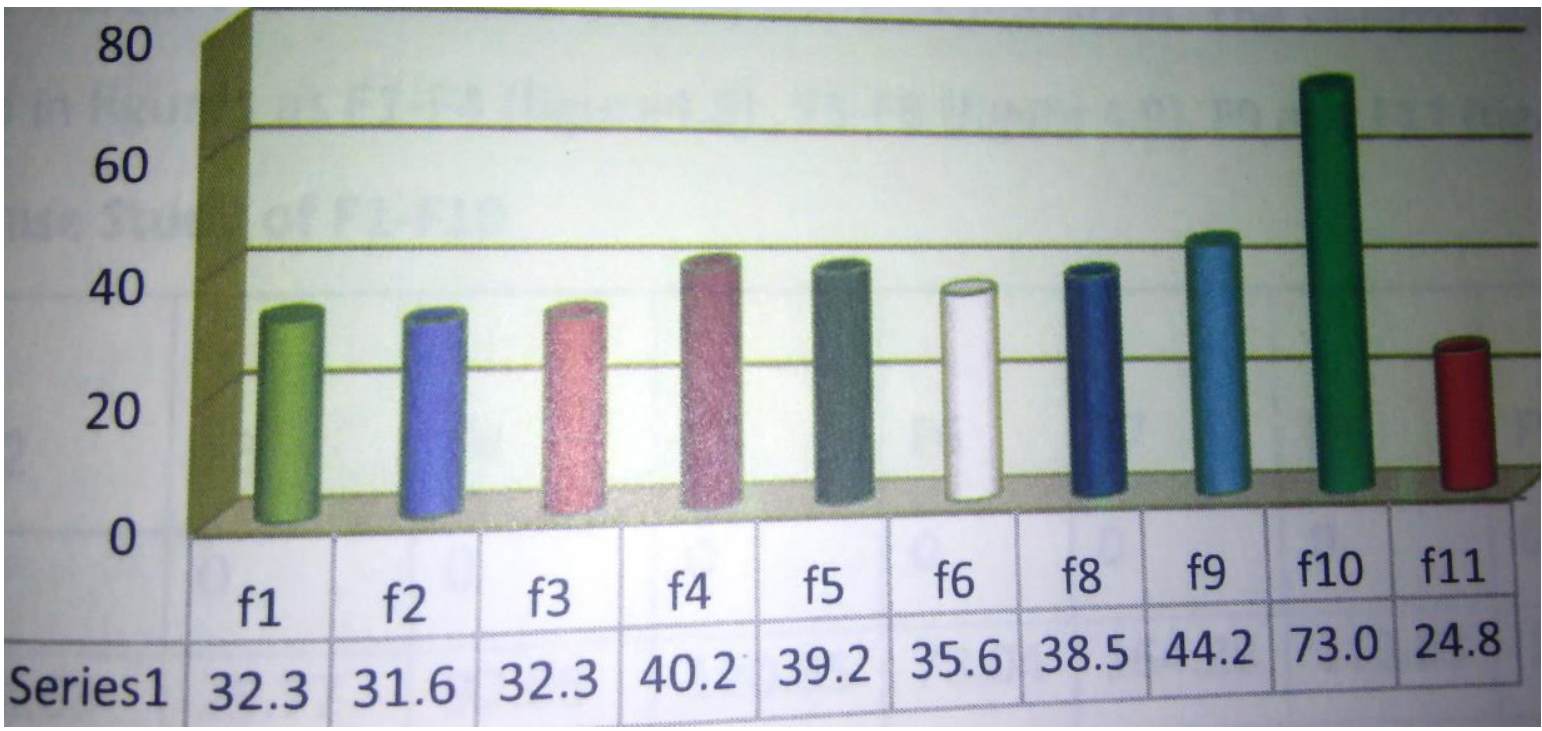

\section{Figure 3.Percent Encapsulation Efficiency of Microspheres}

The drug encapsulation was increased with increase in drug -polymer ratio for F1the \% Encapsulation was $32.3 \%$ with drug polymer ratio of $1: 2$. With same ratio optimum $\%$ Encapsulation of 73 \% was observed in F10. It may be due to Chitosan Complex Present in F10. F7 Spheres were not In Shape it was not included for characterization.

\section{DSC and TGA analysis}

The DSC - TGA Thermo gram of selected formulation std. Levofloxacin and F10 shows there were no interaction between drug and polymers used in F10. Moisture Loss was observed with change in enthalpy of F10 Higher temperature may be due to other excipients in F10.(Flgure 4,5 ).

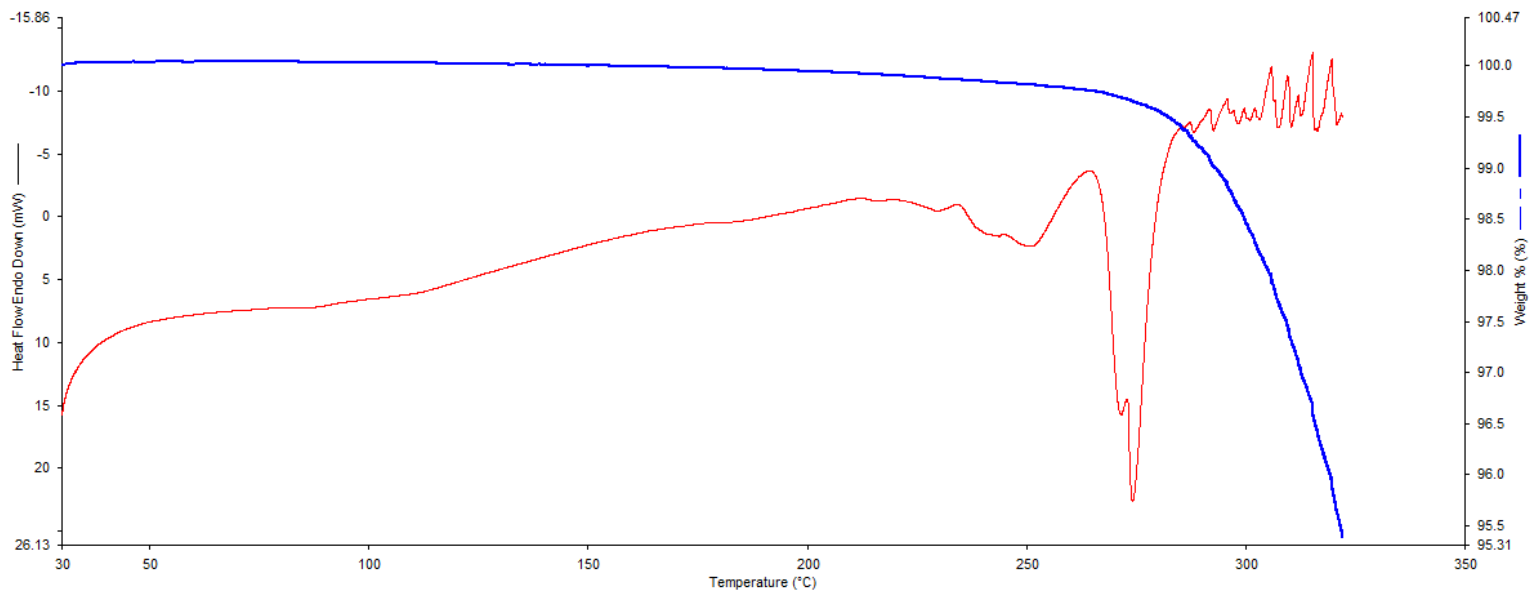

Figure 4.DSC and TGA study of Levofloxacin hemihydrate 


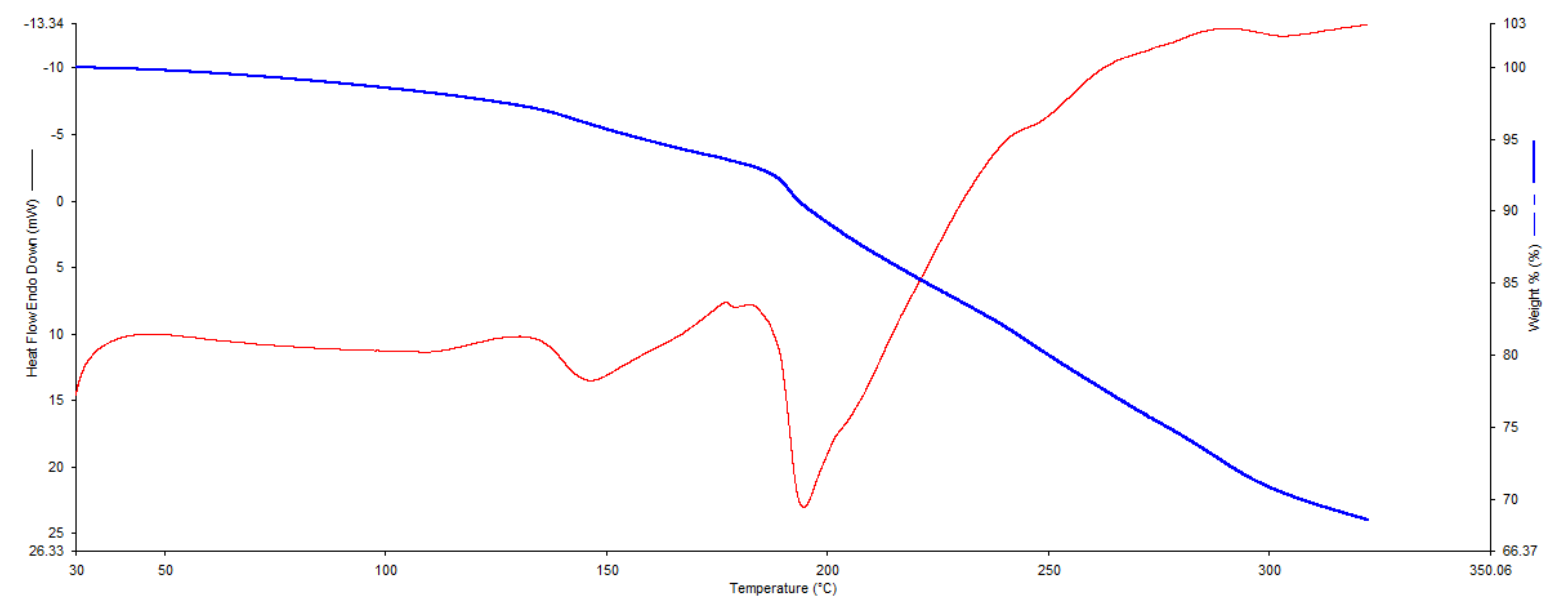

Figure 5. DSC and TGA study of F10

\section{FTIR Analysis}

FTIR spectra were confirmed the Characteristics peaks compared with FTIR of Std. levofloxacin (Figure 6,7).

\begin{tabular}{|l|l|l|}
\hline Frequency $\mathrm{cm}^{-1}$ & Frequency $\mathrm{cm}^{-1}$ & Possible groups assignment \\
Levofloxacin & Sample of levofloxacin & \\
\hline 3427 & 3427.51 & Free Carboxylic-group (COOH). (Stretch) \\
\hline $3100 \mathrm{~cm}-1$ & $3043.67,2935.66,2866.22$ & - C-H stretch of alkenes \\
\hline 1724 & 2833.3 & \\
\hline 1600 & 1724.72 & - vibration of the carbonyl bond (C=O) (stretch) \\
\hline
\end{tabular}

Table 2.0 FTIR Interpretation of Formulation F10. 


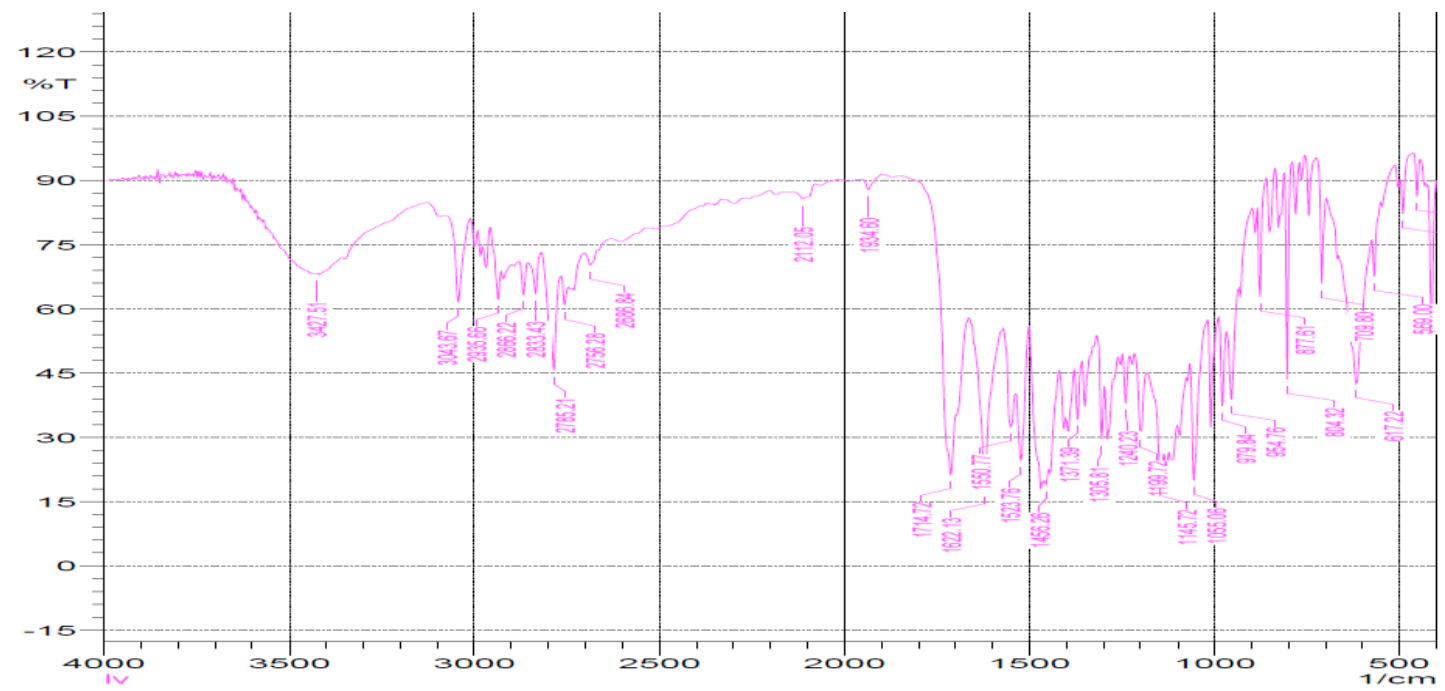

Figure 6. FTIR of Levofloxacin hemihydrate

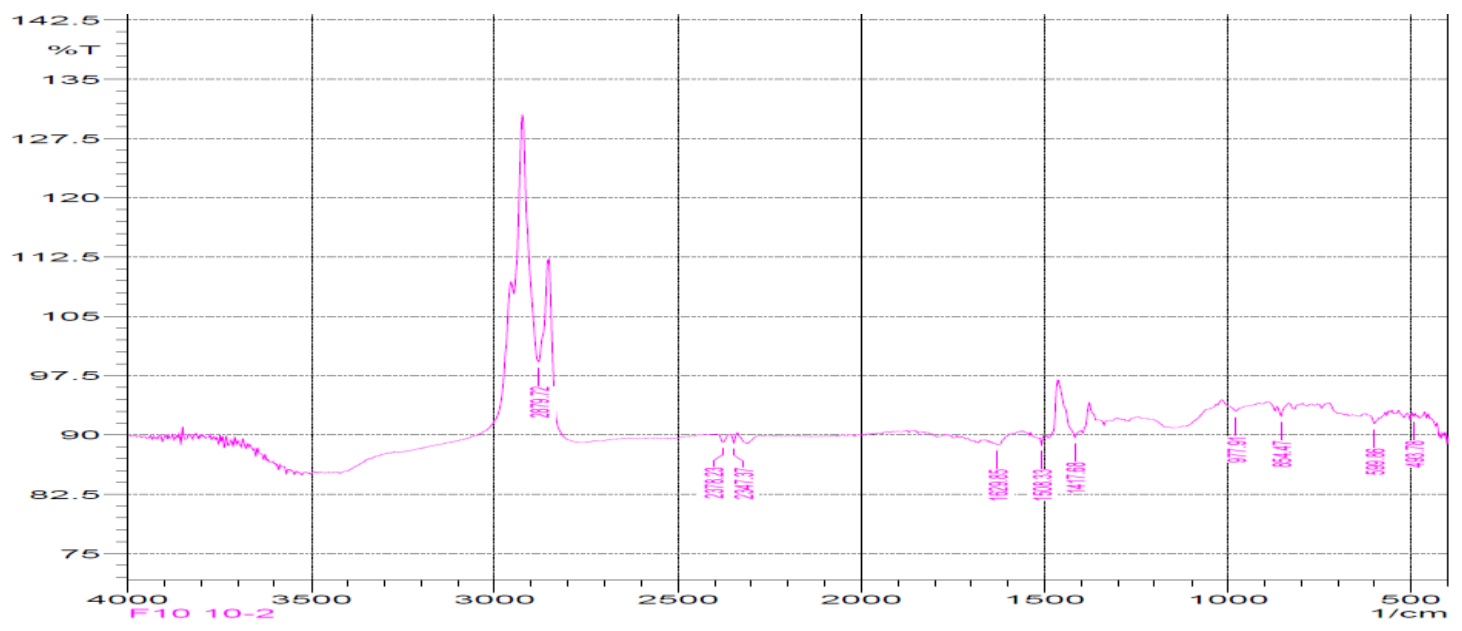

Figure 7.FTIR of F10 


\section{Particle Size Analysis}

The particle size of prepared microspheres was determined by optical microscopy. Mean particle size was in range of $1.43 \pm 0.2$ to $3.08 \pm 0.45 \mu \mathrm{m}$. the mean particle size of F10 was $2.24 \pm 0.1$.

\section{Scanning electron microscopy (SEM)}

The surface morphology of F10 Microspheres was evaluated by SEM, it was observed that F10 Microspheres were Spherical in shape, with porous and rough surface. (Figure 8) and cross section of F10 shows embedded matrix of Calcium Alginate, Chitosan and levofloxacin (Figure 9).

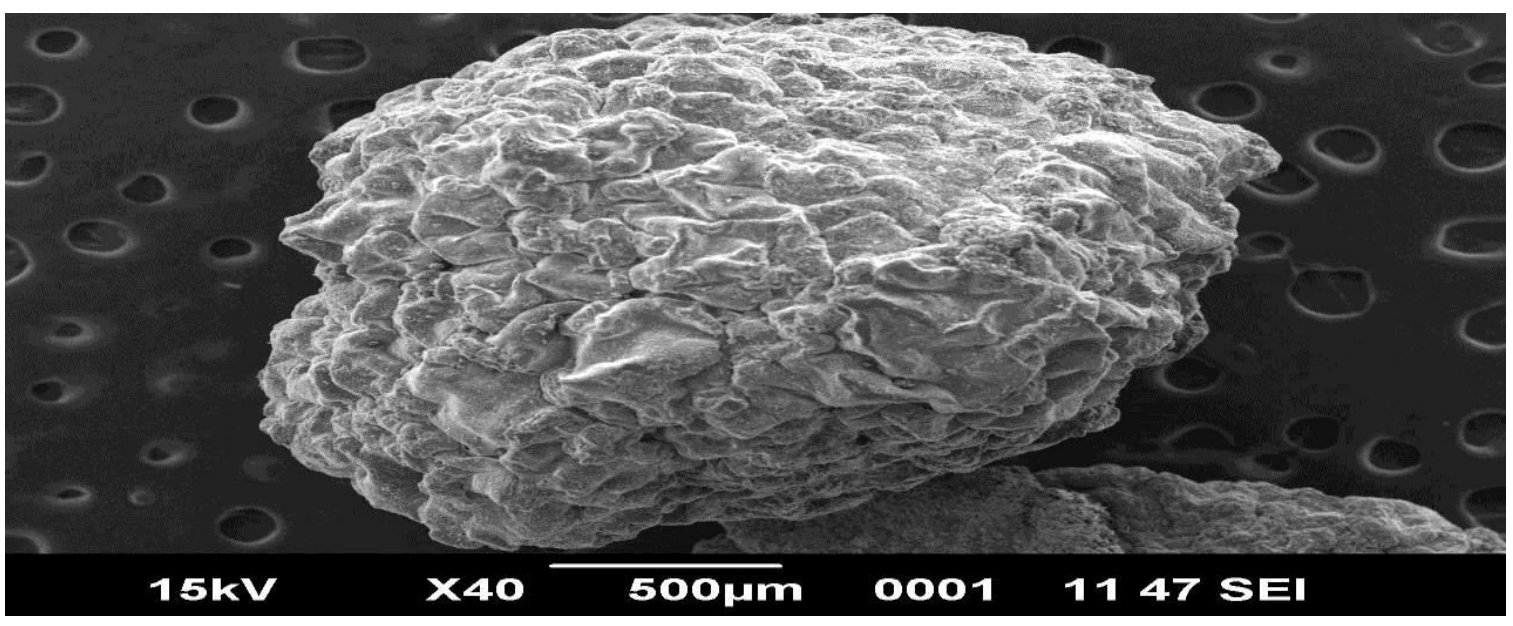

\section{Figure 8.SEM of F10 Microsphere}

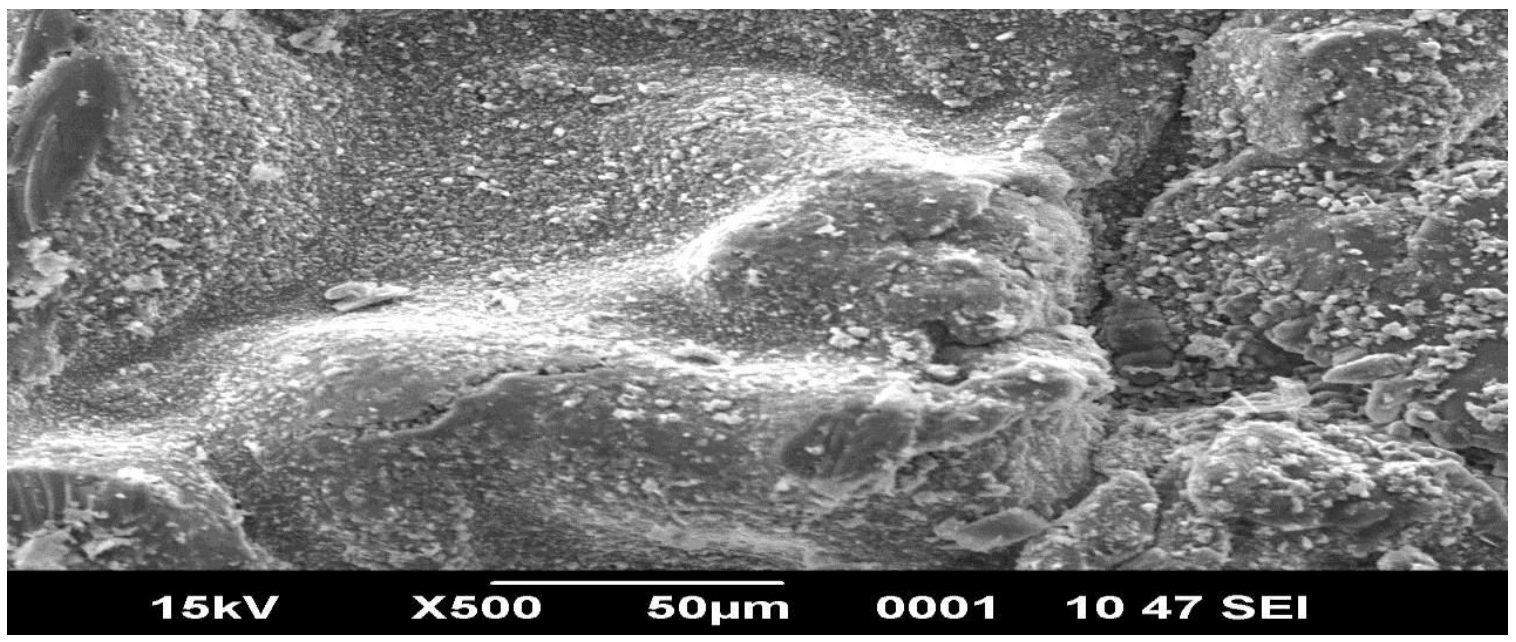

Figure 9. SEM of Cross Section of F10 Microsphere 


\section{Buoyancy Test}

The F10 Shows $100 \%$ buoyancy, with buoyancy time Raft of $255 \mathrm{sec}$ and F10 shows 12 Hrs of Floating Time, confirmed the floating Behavior of F10.

\section{In-vitro Drug Release of F10}

The F10 showed increased release of drug as compare to other formulations the $\%$ cumulative release of F10 at the end of 9 hrs was found to be $134.29 \%$, the \% Drug release Vs Time ( Hrs) Represented in Figure 10.

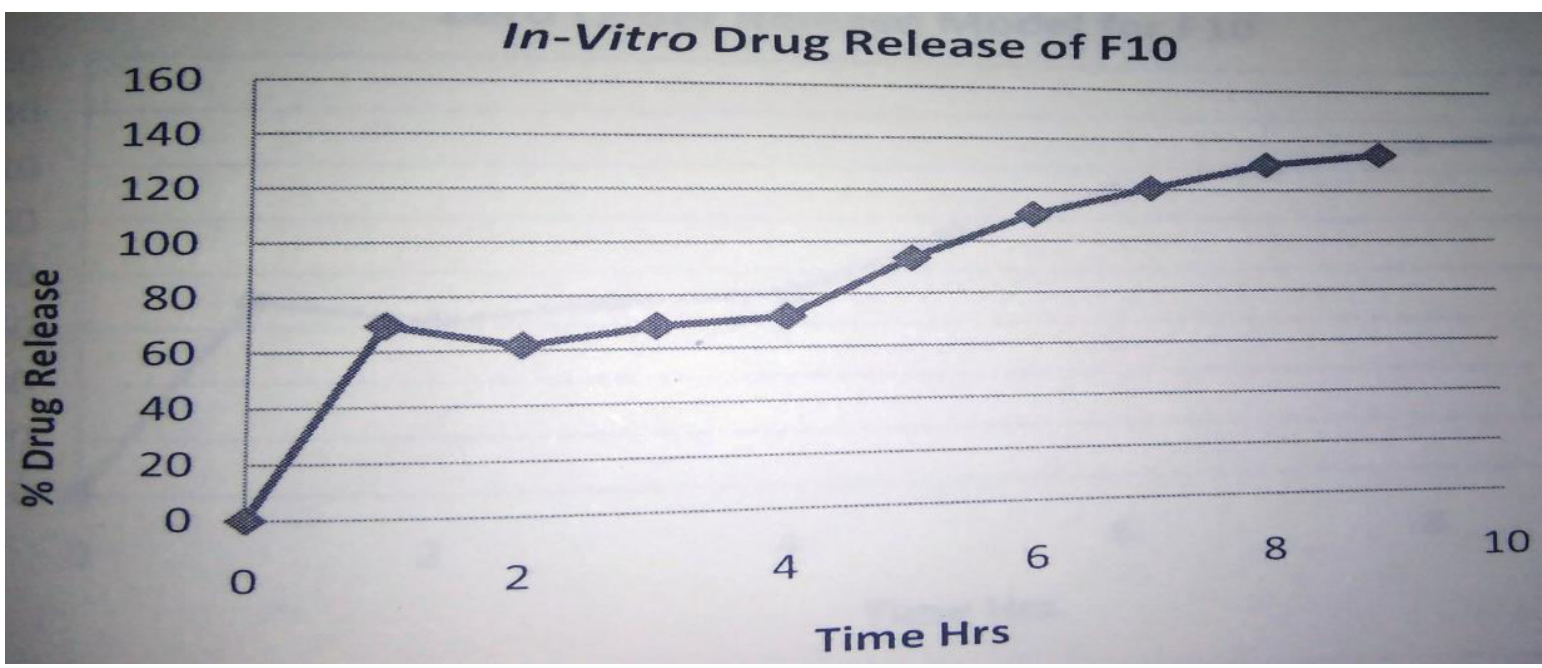

Figure 10. In-vitro drug release from F10 Microspheres

\section{Drug release kinetics}

The drug release kinetics of F10 was studied by Fitting release data in various kinetic models as zero order, first order ,Higuchi's model, Koresmeyer Peppas model . the regression coefficient $\left(R^{2}\right)$ Values Were Obtained The best linearity was found in Higuchis Equation Plot $\left(\mathrm{R}^{2}=0.9310\right)$ Indicating the release of the drug from matrix as Square Root of time dependent process based on fickian diffusion. The other model data represented in table 3.0 and Figure11.

\begin{tabular}{|l|l|l|l|}
\hline Zero Order & First Order & Higuchi Equation & $\begin{array}{l}\text { Koresmeyer Peppas } \\
\text { Equation }\end{array}$ \\
$\mathrm{Q}=\mathrm{K}_{0} \mathrm{t}$ & $\operatorname{In}(100-\mathrm{Q})=\operatorname{In}\left(\mathrm{Q}_{0}\right)-\mathrm{K}_{1} \mathrm{t}$ & $\mathrm{Q}=\mathrm{K}_{\mathrm{H}} \mathrm{t}^{1 / 2}$ & $\mathrm{Log}(\mathrm{Q} / 100)=\mathrm{k}_{\mathrm{P}} \mathrm{t}^{\mathrm{n}}$ \\
\hline $\mathrm{R} 2=0.8759 / \mathrm{K}_{0}=14.92$ & $\mathrm{R} 2=0.9124 / \mathrm{K}_{1}=0.0$ & $\mathrm{R} 2=0.9310 / \mathrm{K}_{\mathrm{H}}=44.76$ & $\mathrm{R} 2=0.7452 / \mathrm{kP}_{\mathrm{P}}=0.0142$ \\
\hline
\end{tabular}

Table 3.0 Drug Release Kinetics for F10. 

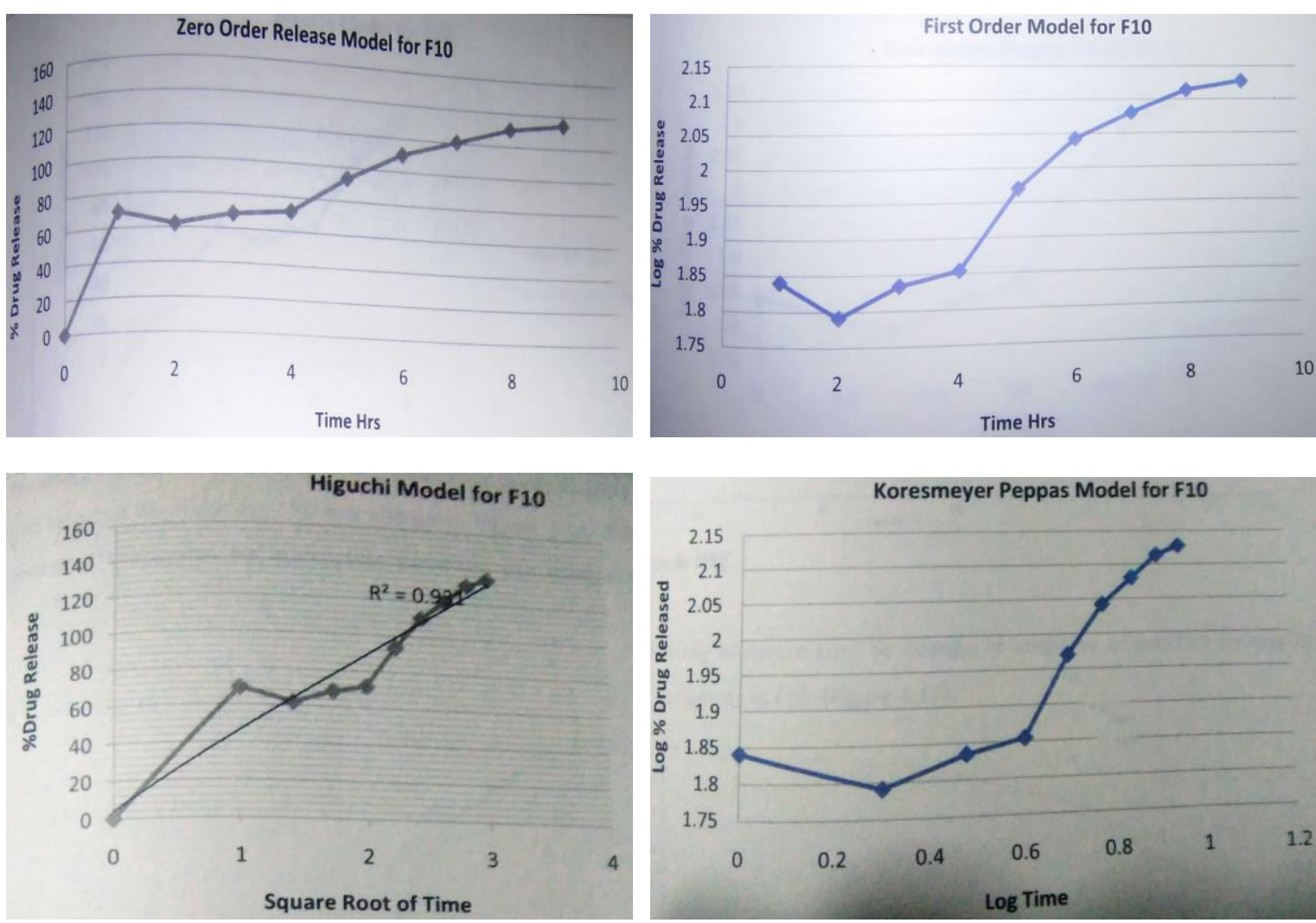

Figure 11. Drug Release Kinetics of F10 Microspheres.

Acknowledgments: the authors are thankful to Institute of chemical technology, Mumbai for DSC and TGA analysis and SAIF Kochi, for SEM analysis.

Conflicts of Interest: “The authors declare no conflict of interest."

\section{References:}

1 Bhardwaj, Lovenish.; Sharma, Pramod Kumar.; A short review on gastro retentive formulations for stomach specific drug delivery: special emphasis on floating in situ gel systems; Afr. J. Basic. App. Sci. 3, 2011, 300-312.

2. Gopalakrishnan S.; And Chenthilnathan, A.; Floating Drug Delivery Systems: A Review, J. Pharm. Sci. Technol. 3 2011, 548-554.

3. Rao, G.U.; And Pavan, M.; Buoyant Sustained Release Drug Delivery Systems Current Potentials Advancements And Role Of Polymers: A Review, Pharmacie Globale Ind.J.Clin.Pharm. 3, 2012, 1-5.

4. Mathur, P.; and Saroha, K.; Floating Drug Delivery System: An Innovative Acceptable Approach in Gastroretentive Drug Delivery, Arch. App. Sci. Res. 2, 2010, 257-270.

5. Bhoyar , P .K.; And Baheti J.R.; An Overview Of A Gastroretentive Floating Drug Delivery System, World. J. Pharm.Res. 1, 2012, 22-40. 
6. Nasa, P.; And Mahant, S.; Floating Systems: A Novel Approach Towards Gastroretentive Drug Delivery Systems, Int. J Pharma And Pharm Sci, 2, 2010, 2-7.

7. Shah, S.H.;And Patel ,J.K.; Stomach Specific Floating Drug Delivery System: A Review, Int. J. Pharm Tech Res, 1,2009 ,623-633.

8. Reddy, M.S. and Kumar; V.M.; Approches to Gastro Retentive Drug Delivery Systems: An Overview, Int. J. Rev. Life. 1, 2011, 62-75.

9. Talwar , N.; Sen H., Staniforth J.N, Orally Administered Controlled Drug Delivery System Providing Temporal And Spatial Control, US Patent 6261601, 2001.

10. Ozdemi , N.; Ordu, S.; Ozkan, Y.; Studies Of Floating Dosage Form Of Furosemide: In Vitro And In Vivo Evaluation Of Bilayer Tablet Formulation, Drug Dev. Ind. Pharm.26 ,2000, 857-866.

11. Penner, G.; And Lustig, K.; Jorg , P.V.G.; Expandable Pharmaceutical Forms. US Patent 5, 1997, 651-985.

12. Sheth ,P. R.; And Tossounian, J.; Drug .Dev. Ind .Pharm, 10, 1984, 313-339.

13. Whitehead, L.; And Fell, J.T.; Collet JH; Eur .J. Pharm Sci. 4, 1996, 182.

14. Kawashima, Y.; And Niwa, T.; Takeunchi, H.; Hino,T.;Itoh ,Y.J.; Pharm Sci, 81 , 135-140, 1992.

15. Ikura, H.; And Suzuki Yoshiki.; Oral Sustained Release Pharmaceutical Preparation US Patent 4, 777, 033, 1988.

16. A.H.EI-Kamel, Sokar, S.M.; Gamal, S.S AI. ; Preparation And Evaluation Of Ketoprofen Floating Oral Delivery System, Int. J. Pharmaceutics, 220 ,2001,13-21.

17. Kawashima ,Y.; Niwa ,T.; Takeuchi ,H.; Hino, T.; And Ito ,Y.; Preparation Of Multiple Unit Microspheres With Acrylic Resin Containing Tranilast And Their Drug Release Characteristics And Floating Behaviour, J .Control Release, 16 ,1991,279-290.

18. Foldager, J.; Toftkjor ,H.; Antacid Composition.US Patent 5068109, 1991.

19. Hamao, Umezawa.; Pepstatin Floating Minicapsules U.S. Patent Number 4, 101, 650, 1978.

20Barhate, D.S. Dr.; and Rupnar ,Y.; Formulation Optimization of Bilayer Floating Tablet Of Famotidine, International J. Pharma . Biosci. 1, 2010.

21. Kumar,D.P.; and Rathnam, G.; Formulation And Characterization of Bilayer Floating Tablets Of Ranitidine, Rasayan J.Chem, 3 , 2010, 368-374.

2017 by the authors. Submitted for possible open access publication under the terms and conditions of the Creative Commons Attribution (CC BY) license (http://creativecommons.org/licenses/by/4.0/). 